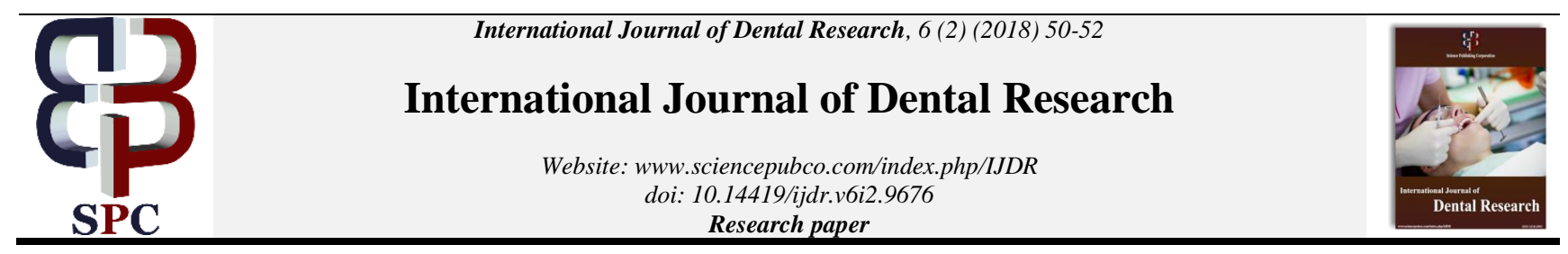

\title{
Adequacy of molar distalization after second and third molar eruption- a case report
}

\author{
Sarath Babu Balina ${ }^{1 *}$,Durga Harsha G V ${ }^{2}$, Padmapriya C V ${ }^{3}$, Varma DPK ${ }^{4}$, Goutham C $\mathbf{V}^{5}$ \\ ${ }^{1}$ Senior Lecturer, St Joseph Dental College, Eluru \\ ${ }^{2}$ Senior Lecturer, Vishnu Dental College, Bhimavaram \\ ${ }^{3}$ Professor\& Head, Vishnu Dental College, Bhimavaram \\ ${ }^{4}$ Professor, Vishnu Dental College, Bhimavaram \\ ${ }^{5}$ Professor, Vishnu Dental College, Bhimavaram \\ *Corresponding author E-mail:padmapriyacv@vdc.edu.in
}

\begin{abstract}
Adult patients with class II malocclusion can be treated routinely by extraction therapy. In the recent decades there was increasing popularity towards non-extraction treatment. Distalization of maxillary molars is one of the prime treatment modality to correct mild to moderate class II malocclusion cases with esthetically acceptable profile. A 16 years old female patient reported with irregularly placed upper front teeth and was diagnosed as Angle's Class II malocclusion with orthognathic maxilla and mandible, average growth pattern. Treatment was planned to distalize the entire maxillary arch using mini implants as skeletal anchorage. $4.0 \mathrm{~mm}$ of maxillary molars were distalized, class I molar and canine relation were achieved bilaterally within span of 10 months without altering the patient's existing profile.
\end{abstract}

Keywords:Class II; Distalization; Mini Implants; Zygomatic Buttress; Third Molars

\section{Introduction}

The foremost aim of an orthodontist is to give esthetic and harmonious profile to the patient. Class II malocclusion is one of the most commonly encountered problem among orthodontic patients. Previously, extraction is considered as a prime modality to gain space and correct this discrepancy. But the need for extraction has been reduced with the recent advances and developments in material, mechanotherapy \& changes in concepts. In patients with straight profile having dentoalveolar discrepancies, extraction of premolars and retraction may lead to dished in profiles. In such conditions, distalization provides scope to correct without affecting the profile.

The success of molar distalization mainly depends upon timing of treatment, which should be ideally, prior to the eruption of second molar. With the advent of newer techniques, successful distalization can be achieved even after the eruption of second molars. ( Ghosh, J.\& Nanda RS 1996, Flores-Mir C et al. 2012). Several intraoral and extraoral appliances are advocated to distalize the molars, which requires patient compliance and with some intraoral appliances, anchor loss at premolar and incisor regions is inevitable. We could overcome by the introduction of the skeletal anchorage devices. They can produce tooth movement or growth modification without resulting in adverse effects on the anchor units with minimal patient cooperation (Yamada K 2009 et al, Fudalej P et al 2011).

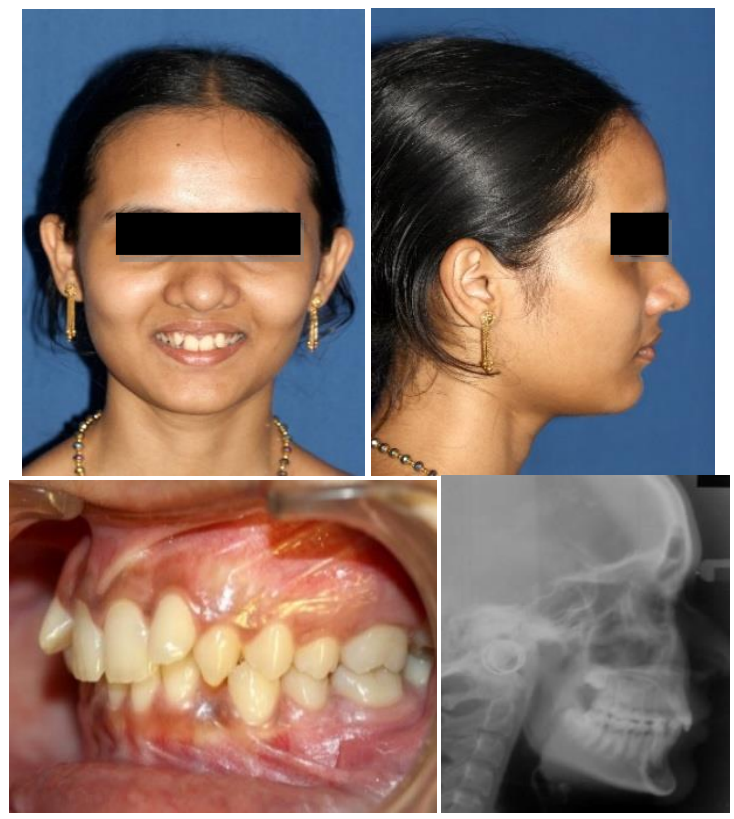

Figure 1: Pretreatment: Class II Malocclusion

\section{Case report}

\subsection{Diagnosis}

A 16-year-old female patient presented with the chief complaint of irregularly placed upper front teeth. Extraoral examination revealed mesoprosopic facial form and mild convex profile with competent lips. Intraoral examination showed end on molar 
relation bilaterally, retroclined maxillary central incisors and labially inclined maxillary lateral incisors with $5 \mathrm{~mm}$ overjet and $4 \mathrm{~mm}$ overbite (Fig.1). Panaromic radiograph examination showed presence of fully erupted teeth upto second molars, upper third molars in Nolla's stage 6 and lower third molars in Nolla's stage7 with adequate bone levels and without any malformations. Cephalometric analysis confirmed skeletal class I relationship $\left(\mathrm{ANB}=4^{\circ}\right)$ along with average growth pattern $\left(\mathrm{GoGN}=27^{\circ}\right.$ and FMA $=25^{\circ}$ ). Treatment objectives were to achieve class I molar and canine relation and relieve the crowding in both maxillary and mandibular arches without altering the facial profile. Treatment plan was to distalize the maxillary second molars with cantilever spring followed by distalization of entire maxillary segment with NiTi coil spring by placing miniimplants at zygomatic maxillary buttress. Since the patient profile is esthetically acceptable, non extraction was planned.

\subsection{Treatment progress}

In both maxillary and mandibular arches, preadjusted edgewise appliance 0.022 "x 0.028 " were bonded. Second molars on either side were distalizied with the help of cantilever spring for 3 months (Fig. 2a). The cantilever spring was made of 21 gauge stainless steel wire. After $4.5 \mathrm{~mm}$ of second molar distalization, the molar was stabilized with nance palatal button. Simultaneously both upper and lower arches were levelled and aligned with 19 " $\mathrm{x}$ 25 " stainless steel rectangular archwire.

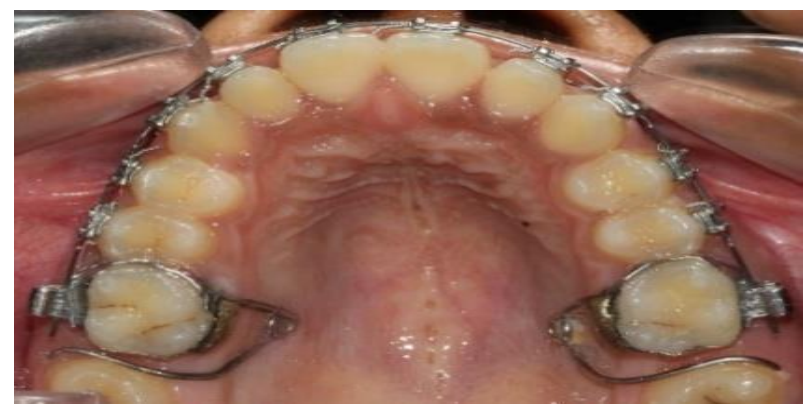

Figure 2a: Distalisation with Cantilever spring

Later Dentos titaniummini-implant of $1.2 \mathrm{~mm}$ diameter and $8.0 \mathrm{~mm}$ length was inserted at zygomatic buttress area on eitherside and NiTi closed coil spring was placed from these implants to canine hooks to distalize the entire arch till the class I molar relation was achieved (Fig. 2b).

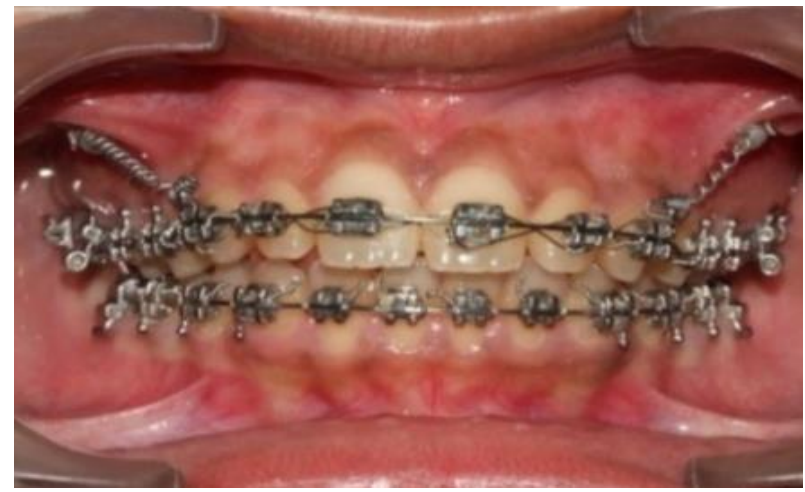

Figure 2b: NiTi Closed coill springs

The retraction was completed within 7 months and final occlusion settling was carried out with elastics for 3 months. After 13months of active treatment, the fixed appliances were removed and upper and lower Hawley retainers were delivered to wear full time for one year post treatment and night time for subsequent years.

\subsection{Treatment results}

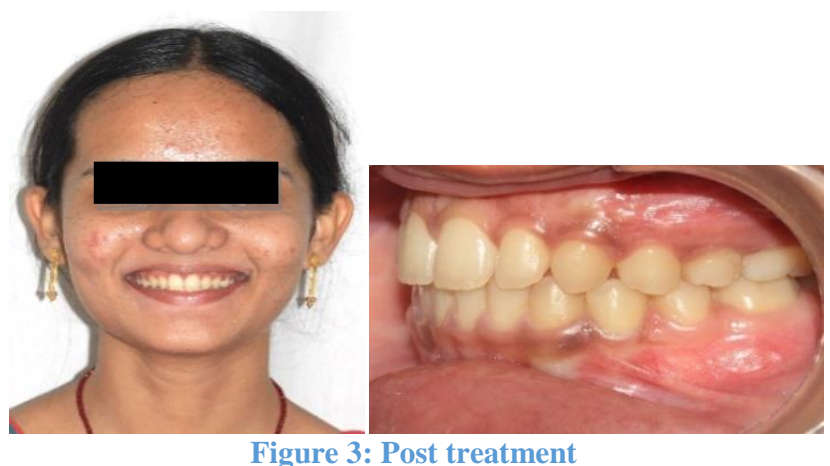

After visualizing the post treatment records, full-cusp class I molar and canine relationship and was achieved on both the sides (Fig. 3 ). Both maxillary molars were distalized without proclining the anteriors with the use of mini implants and crowding was relieved, ideal overjet and overbite was also achieved without significant profile change. Panoramic radiograph showed ideal root parallelism without significant root and alveolar bone resorption.

Since the patient was cooperative treatment results were stable even after 2 years follow up.

Table 1: Cephalometric Analysis during Orthodontic Treatment

\begin{tabular}{|c|c|c|c|c|}
\hline $\begin{array}{l}\text { Measure- } \\
\text { ments }\end{array}$ & $\begin{array}{l}\text { Before } \\
\text { distaliza- } \\
\text { tion }\end{array}$ & $\begin{array}{l}\text { After dis- } \\
\text { talization }\end{array}$ & $\begin{array}{l}\text { Aftertreat- } \\
\text { ment }\end{array}$ & $\begin{array}{l}2 \text { Years } \\
\text { post } \\
\text { reten- } \\
\text { tion }\end{array}$ \\
\hline SNA & $85^{\circ}$ & $84^{\circ}$ & $84^{\circ}$ & $84^{\circ}$ \\
\hline SNB & $81^{\circ}$ & $81^{\circ}$ & $81^{\circ}$ & $81^{\circ}$ \\
\hline ANB & $4^{\circ}$ & $3^{\circ}$ & $3^{\circ}$ & $3^{\circ}$ \\
\hline Wits (mm) & 3 & 2 & 2 & 2 \\
\hline FMA & $25^{\circ}$ & $26^{\circ}$ & $26^{\circ}$ & $26^{\circ}$ \\
\hline SN - GoGn & $27^{\circ}$ & $28^{\circ}$ & $28^{\circ}$ & $28^{\circ}$ \\
\hline UI to $\mathrm{SN}$ & $98^{\circ}$ & $103^{\circ}$ & $102^{\circ}$ & $102^{\circ}$ \\
\hline UI to NA & $14^{\circ}$ & $23^{\circ}$ & $22^{\circ}$ & $22^{\circ}$ \\
\hline $\begin{array}{l}\text { UI to NA } \\
(\mathrm{mm})\end{array}$ & 3 & 5 & 4.5 & 4.5 \\
\hline LI to NB & $27^{\circ}$ & $30^{\circ}$ & $29^{\circ}$ & $29^{\circ}$ \\
\hline $\begin{array}{l}\text { LI to NB } \\
(\mathrm{mm})\end{array}$ & 5 & 4 & 4 & 4 \\
\hline IMPA & $95^{\circ}$ & $99^{\circ}$ & $98^{\circ}$ & $98^{\circ}$ \\
\hline U1-PtV (mm) & 57 & 59 & 59 & 59 \\
\hline U6-PtV (mm) & 25 & 21.5 & 21 & 21 \\
\hline Overjet (mm) & 5 & 2 & 2.5 & 2.5 \\
\hline $\begin{array}{l}\text { Overbite } \\
(\mathrm{mm})\end{array}$ & 4 & 3 & 3 & 3 \\
\hline $\begin{array}{l}\text { Lower lip - } \\
\text { E-line (mm) }\end{array}$ & -5 & -4 & -4 & -4 \\
\hline $\begin{array}{l}\text { Upper lip - E- } \\
\text { line (mm) }\end{array}$ & -7 & -6.5 & -6.5 & -6.5 \\
\hline $\begin{array}{l}\text { Nasolabial } \\
\text { angle }\end{array}$ & $97^{\circ}$ & $100^{\circ}$ & $98^{\circ}$ & $98^{\circ}$ \\
\hline
\end{tabular}

\section{Discussion}

Distalization of entire arch is often challenging with routinely used intraoral appliances. They often cause undesirable side effects like proclination of anteriors and reciprocal mesial movement of molars during retraction of anteriors which occurs in the later stage of treatment. (Park HS et al. 2005, Keles A. 2000). To minimize these side effects skeletal anchorage devices were used in the present case for entire maxillary arch distalization.

As the implant was positioned in the zygomatic buttress away from the posterior teeth, distal movement of teeth was not hampered (Patil. $\mathrm{N}$ et al. 2016). In this case $4 \mathrm{~mm}$ of molar distalization was achieved and $0.5 \mathrm{~mm}$ of relapse was observed, similar to the studies conducted by Suguwara et al (Sugawara J et al. 2004). The average amount of distalization achieved in their study was $3.78 \mathrm{~mm}$ in maxilla and in mandible $3.5 \mathrm{~mm}$. Similarly, Kizinger et 
al also used miniscrew anchorage to distalize the molars with distal jet, they observed $3.92 \mathrm{~mm}$ of distal movement of molars with $0.53 \mathrm{~mm}$ of relapse (Sugawara J et al 2006, Kinzinger GS et al 2009)

With these minimally invasive procedures, we can distalize the entire maxillary arch without any soft tissue alterations, molar rotations and posterior cross bites which are the potential side effects of other intraoral distalizers. Therefore, molar distalization with mini implants is one of the beneficial treatment option to manage non-extraction borderline cases and adolescent growing patients even after eruption of the second molars. Hence, skeletal anchorage provides an excellent resource to bring about the desired movements within short interval.

\section{Conclusion}

Distalization is one of the viable treatment option in mild to moderate class II malocclusions with acceptable profile. So skeletal anchorage devices can be successfully used to distalize the molars bodily without anterior anchorage loss.

\section{References}

[1] Ghosh, J.; Nanda, RS. Evaluation of an intraoral maxillary molar distalization technique, Am J OrthodDentofacial Orthop.110:639646, 1996.https://doi.org/10.1016/S0889-5406(96)80041-2.

[2] Flores-Mir, C.; McGrath, L.; Heo, G.; and Major, PW.:Efficiency of molar distalization associated with second and third molar eruption stage, Angle orthod. 83:735-742, 2012.https://doi.org/10.2319/081612-658.1.

[3] Yamada, K.; Kuroda, S.; Deguchi, T.; Takano-Yamamoto, T.; and Yamashiro, T.: Distal movement of maxillary molars using miniscrew anchorage in the buccal interradicular region, Angle orthod. 79:78-84, 2009.https://doi.org/10.2319/020408-68.1.

[4] Fudalej, P;Antoszewska, J.: Are orthodontic distalizers reinforced with the temporary skeletal anchorage devices effective? Am J OrthodDentofacial Orthop.139:722-729, 2011.https://doi.org/10.1016/j.ajodo.2011.01.019.

[5] Park, HS. Lee, SK.; and Kwon, OW. Group Distal Movement of Teeth Using Microscrew Implant Anchorage, Angle Orthod. 75:602-609, 2005.

[6] Keles, A.; Sayinsu, K.: A new approach in maxillary molar distalization: intraoral bodily molar distalizer, Am J OrthodDentofacial Orthop.117:39-48, 2000.https://doi.org/10.1016/S08895406(00)70246-0

[7] Patil. N.; Kerudi, V.; Patil, HA,;Tekale, PD.; Bonde, P.; and Dolas, S.: Molar Distalization By Miniplates-A Review, Journal Of Applied Dental and Medical Sciences. 2:1, 2016

[8] Sugawara, J.; Daimaruya, T.; Umemori, M.; Nagasaka, H.; Takahashi, I.; Kawamura, H.; and Mitani, H.: Distal movement of mandibular molars in adult patients with the skeletal anchorage system, Am J OrthodDentofacial Orthop.125:130-138, 2004. https://doi.org/10.1016/j.ajodo.2003.02.003.

[9] Sugawara, J.; Kanzaki, R.; Takahashi, I.; Nagasaka, H.; and Nanda R.: Distal movement of maxillary molars in nongrowing patients with the skeletal anchorage system, Am J OrthodDentofacial Orthop.129:723-733,

2006.https://doi.org/10.1016/i.ajodo.2005.08.036.

[10] Kinzinger, GS. Gülden, N.; Yildizhan, F.; and Diedrich, PR.: Efficiency of a skeletonized distal jet appliance supported by miniscrew anchorage for noncompliance maxillary molar distalization, Am J OrthodDentofacial Orthop.136:578-586, 2009.https://doi.org/10.1016/j.ajodo.2007.10.049. 